\title{
Study on the Construction of Agricultural Public Brand Management Mechanism: Based on the Survey of Powder Dry from Chakou in Minqing, Fujian
}

\author{
Feng Qu ${ }^{1}$, Xiaoling Huang ${ }^{1}$ \\ ${ }^{1}$ School of Management, Fujian Agriculture and Forestry University, Fuzhou, Fujian, China
}

Keywords: agricultural public brand; brand dilemma; lemon market

\begin{abstract}
Agricultural public brands have public attributes and it is necessary to establish different management mechanisms to adapt to effective management needs. The paper investigates the agricultural public brand "Powder Dry from Chakou in Minqing" by means of literature, field investigation and interview, and studies the problems in brand management based on the theory of lemon market, and constructs a system of agricultural public brand management mechanism to provide reference for the effective management of agricultural public brands.
\end{abstract}

\section{Introduction}

Agricultural public brands have public attributes and need to build effective management mechanisms. Powder Dry of Chakou, as one of the famous local specialty products in Fuzhou City, Fujian Province, it has excellent quality. Similar to other agricultural public brands, the management status of the public brand is still not perfect, and the phenomenon that the brand management is not in place exists objectively, which affects the further development of the agricultural public brand. Therefore, this paper takes the lemon market theory as the basic principle, takes the Powder Dry of Chakou as the survey object, analyzes the management dilemma that the public brand has fallen into due to improper management, and puts forward the corresponding management mechanism.

\section{Research Review}

Lemon market theory is a well-known economic theory model proposed by American scholar Akerlof in 1970. The main idea is that the buyers and sellers in the trading market often have information asymmetry. Under this situation, the seller has the tendency to produce quality speculation ideas to seek improper interests. The buyer intends to maintain his own position when he intends to purchase goods. The benefits in the risk tend to drive down the selling price, and the seller's ability to obtain normal profits will reduce the cost of premium products. As the market advances, excellent products have been excluded from the trading market by inferior products.

Since its introduction, the lemon market model has attracted the attention of a large number of scholars and has been used by previous researchers in various fields of research. For example, Liu Jin and $\mathrm{Li} \mathrm{Yu}$ revealed the "tragedy of the commons" and "lemon market" in the public brands of agricultural products in the region, and put forward the strategy of brand standardization dissemination[1]; Hu Jin studied various subjects in the lemon market and finally came up with a management strategy corresponding to each subject[2]; Zhou Bo deeply studied the mechanism of governance of the lemon market and believed that the four mechanisms of signal display mechanism, reputation mechanism, quality assurance mechanism and third-party intervention should be adopted to develop and perfect the market system and break through the dilemma of lemon management[3]]and so on, The above management studies used in various fields have laid a certain foundation for this article. However, most of the above studies use the lemon market model from the perspective of economics, and few scholars currently use the lemon market theory to carry out agricultural public intobrands into systematic discussion. Therefore, this article will combine the lemon theory and take "Chafen" noodles as an example, focusing on a comprehensive analysis of the 
management dilemma of agricultural public brands and constructing an anti-lemon agricultural public brand management mechanism system.

\section{The Dilemma of Agricultural Public Brand Management under the Lemon Market Theory}

\subsection{The Powder Dry of Chakou Public Brand Management Dilemma.}

Powder Dry from Chakou made fortune in the village of Chakou Village in Tazhuang Town. Many people made a fortune by inheriting this traditional craft and the economy of the public brand was evident. The goal and slogan of Powder Dry from Chakou noodles is "famous for the world". However, after investigation, it was found that most of the markets for Powder Dry from Chakou are limited to Fuzhou and its surrounding areas. The foreign market acceptance groups are also mostly Chinese who have traveled overseas in and around Fuzhou. These problems should be attributed to the following research findings, such as insufficient incentive for the government to manage and promote public brands, and inadequate self-regulation management.

\subsection{Analysis of Causes of Management Dilemma.}

Information asymmetry. Information asymmetry is an important cause of the lemon market's result, and it is also one of the main factors that cause agricultural public brands to fall into the management dilemma. Information asymmetry in the market means that in a market transaction, the key information possessed by buyers and sellers is not comparable, and the seller often has more transaction information than the buyer, leaving the buyer at a disadvantage. [4]

The consumers will try their best to drive down the price proposed by the seller and will be willing to buy The Powder Dry of Chakou at a lower price in order to avoid asymmetric information harming themselves. For a long time, the quality of The Powder Dry of Chakou will gradually be driven out of the powder dry market by the inferior powder, and the "lemon dilemma" will be formed[5].

Negative economic externalities. As a result of the externality of The Powder Dry of Chakou economic activity, if the above-mentioned adverse circumstances occur, the public brand of Powder Dry of Chakou will inevitably have an economic negative external effect. The bad consequences of the deterioration of the brand reputation will have serious consequences such as the economic downturn of the entire village or even the county and the decline in the level of social and economic welfare.

Missing brand culture. The lack of top-level design for the agricultural public brand is mainly reflected in the lack of a culture-based branding system[6]. However, there is currently a shortage of talented people who manage their brand value through culture. The situation is not optimistic. Therefore, it is imminent to use the local culture to perform top-level design on the cultural value of The Powder Dry of Chakou brand.

\section{Construction of a Public Agricultural Brand Management System}

Agricultural public brand management refers to the maintenance and control of public brands through various means, which enhances the positive image of the brand and maximizes the public brand assets. [7]. In order to effectively improve the management dilemma of public brands with lemon properties, build a four-dimensional agricultural public brand management model of improvement based on the brand quality assurance mechanism, the brand signal mechanism, the brand culture mechanism, and the brand reputation mechanism combined with the above investigation of The Powder Dry of Chakou. It has a progressive and cyclical effect among the various mechanisms, forming a good mechanism of continuous circulation operation.

\subsection{Brand quality assurance mechanism.}

The mechanism of the brand quality assurance mechanism is as follows: The seller promises the quality of the product under the brand and makes corresponding provisions, thereby increasing the cost of seller's speculation behavior and effectively reducing or even eliminating the seller's bad 
speculation and accumulating corporate reputation assets[6].

First, pre-sales standardization is to control the overall quality through the establishment of a public brand product standardization system, which is a front-end approach to eliminate information asymmetry in the lemon theory.

Second, the after-sales protection service is a service provided by the operator to fulfill the promise of returning or compensating products that exceed the scope of quality assurance after the sale of the product[8].Perfecting the construction of pre-sales, in-sale, and after-sales service systems is the most direct and significant signal of quality assurance and can effectively eliminate consumer concerns[9],and lays a good foundation for the reputation mechanism of agricultural public brands.

In addition to manufacturing and disseminating quality assurance signals, I believe that the quality of agricultural public brand products should also be upgraded in order to reduce the cost of service for back-selling commodities and maintain a good corporate reputation. Taking the finer roads is a good way to reduce the possibility of after-sales compensation and improve reputation.

\subsection{Brand signal mechanism.}

The operation principle of the brand signal mechanism is that the brand actively discloses different types of signals to consumers through various channels in its trading market, such as licenses, various media advertisements, and official announcements[10],so that signals can be accurately conveyed to target groups and reduce unfair trade caused by asymmetric information[11].

First, if there is a regional agricultural public brand, the brand signal mechanism should be improved by the certification of geographical indications. Dr. Cao Lin concluded that the certification of geographical indications can effectively eliminate the decrease in demand due to information asymmetry and it is an effective way to transmit quality signals[12].Therefore, in order to improve and effectively operate the brand signal mechanism, the government, the companies and the consumers should pay enough attention to it.

Second, so as to improve the signal propagation mechanism and reduce information loss, establish and improve information systems for all enterprises, such as formulating product quality disclosure systems and establishing corresponding penalties, so that merchants actively disclose product information through various effective channels to achieve unified pricing and transparent quality.

\subsection{Brand culture mechanism.}

The cultural mechanism of the agricultural public brand plays a role by creating creative elements that are extracted from the optimization and combination of various local cultural resources so that the brand has cultural core competitiveness and cultural productivity[13], embedding brand value in the local culture enables consumers to accurately identify the brand due to their special culture, enhancing the ability of the brand signal mechanism to operate.

The construction of a brand culture mechanism requires multiple supportive efforts. In the government's case, relevant policies should be introduced to attract relevant talents to enter the industry in which the agricultural brand is located, and to conduct top-level design from a professional perspective to ensure that the cultural mechanism is unique and in place In the enterprises' case, the public brand value management, operation awareness and brand culture concept should be firmly established with a keen culture [13].

\subsection{Brand reputation mechanism.}

Reputation is the last link in the brand management mechanism, but it can also return to the first ring of the mechanism system, that is, promote the operation of the brand quality assurance mechanism of agriculture. The reputation mechanism of public brands can enable enterprises to choose to refuse temptation to maintain the overall reputation of public brands in the face of the temptation of bad interests, thereby increasing the credibility of the quality assurance mechanism.

First of all, we should establish the public brand awareness in the industry and jointly improve the brand reputation mechanism. First, play the role of industry associations and other institutions to fully mobilize the positive atmosphere of industry self-regulation [14]. But Self-discipline in the industry is a good indication of market self-regulation and will closest distance between the industry and the 
market makes it more flexible and effective than government administrative measures. Second, establish public brand awareness and encourage the use of geographical indications. The use of geographical indications can not only ensure the superior quality of products, but also enable companies to have a link in addition to competition - the use and maintenance of geographical indications together to enhance the brand credit of geographical indication industry clusters [12] . In other words, the common use of geographical indications increases the reputation of the agricultural public brand.

In the next place, all companies should ensure the quality of their products, ensure the effective operation of the quality assurance mechanism, and influence the brand reputation mechanism with the return of the quality assurance mechanism. Therefore, companies should emphasis should be placed on the cumulative effect of quality assurance in the quality assurance mechanism on reputation. Then the mutual influence between them is used to promote the operation of the reputation mechanism, and ultimately promote the normal operation and virtuous circle of the entire agricultural public brand management mechanism system.

\section{Conclusion}

The agricultural public brand is the crystallization of the natural development of a region in its historical development, and it is an important fulcrum for inciting local economic development. The importance of effective management of the region is self-evident. After reviewing a large amount of literature and analysis, the author believes that if the brand management, brand signal, brand culture, brand reputation "four-dimensional integration" agricultural public brand management mechanism combined with the government, enterprises and other relevant departments of multi-party efforts, can not only effectively manage public brand management dilemma under the lemon market but provide reference for effective promotion of brand management.

\section{Acknowledgement}

Supported by the key project of the 2018 Fujian Provincial University Humanities and Social Sciences Research Base of Rural Tourism Research Center.

\section{References}

[1] Liu Jin, Li Wei. Communication Standardization—Development Strategy of Regional Public Brands for Agricultural Products [J].Agricultural Processing, 2010(11).

[2] Hu Jin. Analysis of Market Subjects in the "Lemon Dilemma" of Agricultural Products__Based on the Perspective of Agricultural Products Market under Information Asymmetry [J].Economic Research Guide, 2015(12).

[3] Zhou Bo.Review on the Study of the Management Mechanism of Lemon Market [J].Dynamics of Economics, 2010, (3).

[4] Liu Ying. Analysis of the Dilemma of Agricultural Products Based on Lemon Market Theory [J].E-commerce, 2016(06).

[5] Li Gongkui, Ying Ruiyao. "Lemon Market" and Institutional Arrangement: An Analysis Framework for Guaranteeing the Quality and Safety of Agricultural Products[J].Agricultural Technology \& Economy, 2004, (03).

[6] XU Ji-feng. A Brief Discussion on the Evolution of the "China Blue" Brand_—Rebranding and Top-Level Design Based on TV Ontology [J].Chinese Journal of Broadcasting and Television, 2014(08).

[7] Ma Wenjing. Research on Brand Management of GI Produce Based on the Enterprise Perspective [D]. Tianjin University, 2012. 
[8] Fu Xuzhe,Wang Shoulan,Fan Jinyu,Xu Jialin.Re-understanding of the modern concept of product after-sales service[J].Commodity and Quality,2009(17).

[9] Li Dehua.Influence of Information Asymmetry on Consumer Behavior and Countermeasures [J].Modern Intelligence, 2008, 28(12).

[10] Gao Xiaofei, Liu Hedong. The Lemon Effect and Its Effective Governance in Industrial Clusters [J].Science and Technology Management Research,2011,(20).

[11] Shan Yuyuan, Xie Yaoyao, Liu Xiaohong. Internal Causes and Strategies of Brand Asset Formation Process and Food Product Traceability System Construction: A Study Based on the Mechanism of Signal Mechanisms in Brand Asset Formation [J]. The Study on Business, 2017(11).

[12] Cao Lin. Research on branding mechanism and strategy of geographical indication products [D]. Shandong University, 2012.

[13] Deng Anqiu,Huang Xinping. The Cultural Defects and Governance of China's Own Brand Construction[J].Theory and Practice of Finance and Economics,2007(03).

[14] He Xinfeng, Yang Changming. Analysis and Countermeasures of "Lemon Market" in Industrial Clusters [J].Contemporary Economic Management, 2005(06). 